\title{
Analisa Deformasi Pada Campuran Aspal Beton Menggunakan Derbo dan Wetfix
}

\author{
Winarno Arifin ${ }^{1,6}$, Asma Massara $^{2}$, Andi Alifuddin ${ }^{3}$, Muh.Fahul Ramadhan $^{4}$, Muhammad Tauiq ${ }^{5}$ \\ ${ }_{1,2,3,4,5}$ Program Studi Teknik Sipil Fakultas Teknik Universitas Muslim Indonesia \\ ${ }^{6}$ Universitas Brawijaya
}

Email: ${ }^{1}$ winarno.arifin@umi.ac.id, ${ }^{2}$ asma.massara@umi.ac.id, ${ }^{3}$ andi.alifuddin@umi.ac.id, ${ }^{4}$ fahruljagawana24@gmail.com, ${ }^{5}$ muhtaufiq00@gmail.com

\begin{abstract}
Abstrak
Pada dasarnya jalan akan mengalami penurunan fungsi strukturalnya sesuai dengan bertambahnya umur. Jalan Raya saat ini mengalami kerusakan dalam waktu yang relatif sangat pendek (keruskan dini) baik jalan yang baru dibangun maupun jalan yang baru diperbaiki. (Fadhilah,2012). Banyak hal yang menyebabkan kerusakan pada

Kata Kunci

Deformasi, Derbo dan Wetfix konstruksi jalan, anatara lain akibat pengaruh beban lalu lintas kendaraan yang berlebihan (over loading), temperatur, air (genangan), dan konstruksi perkerasan yang kurang memenuhi persyaratan teknis. Faktor lain seperti perencanaan, pengawasan, pelaksanaan dan lingkungan juga memberikan konstribusi pada kerusakan jalan .Deformasi pada perkerasan jalan lentur, yang biasa disebut (rutting dan geser), Alur biasanya terdiri dari lendutan memanjang yang terjadi pada jalur roda kendaraan, merupakan akumulasi dalam jumlah kecil terjadi deformasi disebabkan oleh adanya peningkatan beban. Kerusakan bisa berkembang lebih parah karena permukaan jalan tidak kedap air lagi sehingga air bisa melemahkan ikatan antara batuan dan aspal Bahan tambah Derbo dan Wetfix dapat memperhambat laju deformasi pada campurn aspal beton
\end{abstract}

Abstract
Basically, the road will experience a decrease in its structural function in accordance
with increasing age. Roads are currently experiencing damage in a relatively very
short time (early roll out) both newly built roads and newly repaired roads. (Fadhilah,
2012). Many things cause damage to road construction, among others due to the
influence of excessive vehicle traffic loads (over loading), temperature, water
(inundation), and pavement construction that does not meet technical requirements.
Other factors such as planning, supervision, implementation, and the environment
also contribute to road damage. Information on flexible pavement, commonly referred
to as (rutting and sliding), Grooves usually consist of longitudinal deflections that
occur in the lanes of vehicle wheels, constituting small amounts of accumulation
deformation occurs due to an increase in load. Damage can develop more severely
because the road surface is not waterproof anymore so water can weaken the bond
between rocks and asphalt Derbo and Wetfix added materials can slow down the rate
of deformation in the concrete asphalt mix

\section{PENDAhULUAN}

Pada dasarnya jalan akan mengalami penurunan fungsi strukturalnya sesuai dengan bertambahnya umur. Jalan Raya saat ini mengalami kerusakan dalam waktu yang relatif sangat pendek (keruskan dini) baik jalan yang baru dibangun maupun jalan yang baru diperbaiki (Sudarno dkk, 2018). Banyak hal yang menyebabkan kerusakan pada konstruksi jalan, anatara lain akibat pengaruh beban lalu lintas kendaraan yang berlebihan (over loading), temperatur, air (genangan), dan konstruksi perkerasan yang kurang memenuhi persyaratan teknis. Faktor lain seperti perencanaan, pengawasan, pelaksanaan dan lingkungan juga memberikan konstribusi pada kerusakan jalan. (George Stefen Muaya dkk, 2015). 
Deformasi permanen pada perkerasan jalan lentur, yang biasa disebut (rutting dan geser), Alur biasanya terdiri dari lendutan memanjang yang terjadi pada jalur roda kendaraan, merupakan akumulasi dalam jumlah kecil terjadi deformasi disebabkan oleh adanya peningkatan beban (Badron dkk, 2019). Kerusakan bisa berkembang lebih parah karena permukaan jalan tidak kedap air lagi sehingga air bisa melemahkan ikatan antara batuan dan aspal (Syaifullah, 2016) (Chalid, 2016). Melemahnya ikatan batuan dan aspal akan menyebabkan lepasnya butiran-butiran batuan sehingga akan terjadi lubang pada perkerasan jalan (Hafidz, 2020). Jika di atas permukaan jalan yang mengalami rutting diberi lapis tambahan perkerasan baru, maka akan terjadi retak refleksi pada lapis tambahan tersebut (Rizal \& Susilowati, 2019) (Susilowati \& Wiyono, 2017). Rutting refleksi ini terjadi akibat kelemahan yang terdapat pada lapis perkerasan lama akan berkembang ke atas masuk ke dalam lapis perkerasan baru (Huwae, 2015). Rutting pasa lapisan tambahan akan terjadi saat gayagaya geser dan tekuk akibat beban lalulintas berat melampaui kekuatan lapis aspal tambahan. (Walt $d k k, 2004)$.

Sorong biasanya ditempatkan pada bagian pengambilan dan bangunan bagi sadap balk itu sekunder maupun tersier. Selain itu, alat ini juga dapat digunakan Perkembangan berbagai sector mengakibatkan peningkatan pergerakan lalu lintas, baik pergerakan barang maupun manusia. Untuk menunjang kelancaran dalam pergerakan lalu lintas dibutuhkan sarana dan prasarana pendukung. Salah satu prasarana transportasi yang memiliki peranan penting yaitu jalan (Fisu, 2019). Untuk mengoptimalkan maka diperlukan inovasi baru seperti aspal yang dimodifikasi. Salah satunya adalah menambahkan campuran dengan menggunakan bahan tambah zat aditif sebagai anti stripping dalam pencampuran aspal. Zat aditif terdiri dari dua jenis yaitu anti stripping agent Derbo dan Wetfix. Zat aditif Derbo adalah jenis anti stripping agent berupa cairan yang berasal dari India. Zat aditif Wetfix adalah jenis anti stripping agent berupa cairan, bahan tambah ini di peroleh dari PT. ADHI KARYA.

Berdasrakan manual pemeliharaan jalan No : 03/MN/B/1983 yang di keluarkan oleh Direktorat Jendral Bina Marga, kerusakan jalan dapat dibedakan menjadi : retak (cracking), distorsi (distortion), cacat permukaan (disintegration), pengausan (polished aggregate), kegemukan (bledding orflushing) dan penurunan pada bekas penanaman utilitas (utility cut depression). Kerusakan jalan berupa cacat permukaan (disintegration) terdiri dari beberapa jenis, salah satunya yaitu berupa pengelupasan lapisan (Roder dkk, 1993). Durabilitas beton sangat penting untuk penentuan ketahanan terhadap berbagai kondisi lingkungan (Sulaiman \& Fisu, 2020) (Sulaiman dkk, 2018).

Tujuan dari penelitian ini yaitu mengetahui karakteristik campuran beton aspal terhadap penambahan zat aditif anti stripping agent (Derbo) dan anti stripping agent (Wetfix), serta untuk mengetahui tingkat Deformasi campuran beton aspal dengan menggunakan anti stripping agent (Derbo) dan anti stripping agent (Wetfix).

\section{METODE PENELITIAN}

\subsection{Lokasi Penelitian}

Lokasi penelitian dilakukan di Laboratorium Jalan Raya dan Transportasi Program Studi Teknik Sipil Fakultas Teknik Universitas Muslim Indonesia dengan menggunakan saluran terbuka.

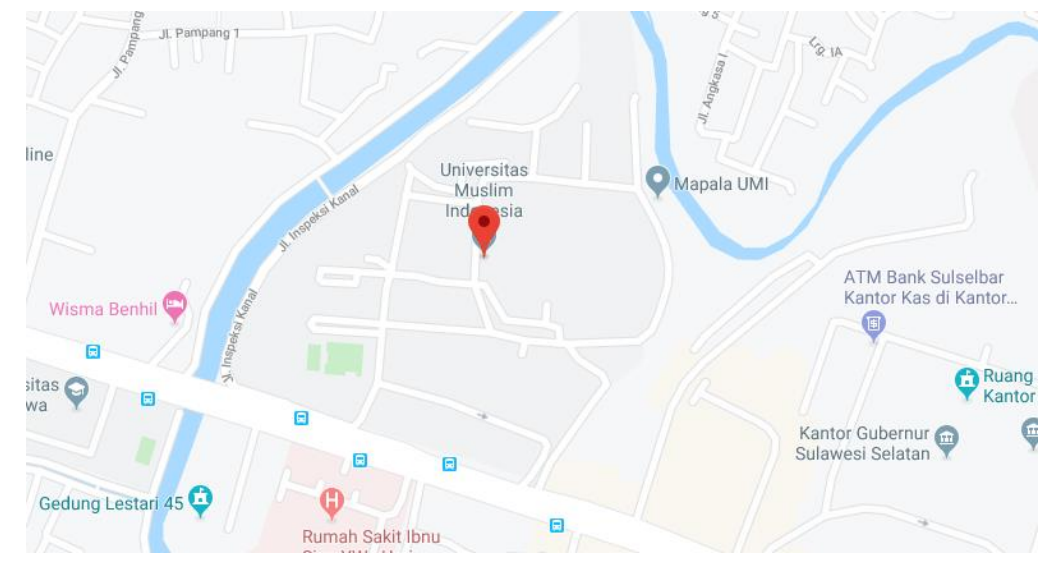




\subsection{Alat dan Bahan}

Gambar 1. $P$ lokasi penelitian

Sumber: Google maps peta kota makassar

Bahan yang digunakan Aspal yang digunakan yaitu aspal minyak penetrasi 60/70 (AC 60/70) produksi Pertamina yang diperoleh dari PU Bina Marga Baddoka. Agregat yang di gunakan yaitu agregat kasar dan halus yang diambil di Bili-bili, disatukan kemudian dilakukan pengambilan sampel di laboratorium dengan metode perempatan yang mewakili sampel lainnya, Anti stripping agent (Derbo) di ambil dari PU Bina Marga Baddoka dan anti stripping wetfix di ambli dari PT. Adhi Karya.

Alat - alat yang digunakan yaitu:

Menggunakan alat-alat yang tersedia di Laboratorium Jalan Raya dan Transportasi Program Studi Teknik Sipil Fakultas Teknik Universitas Muslim Indonesia.

Percobaan ini dilakukan pada saluran, adapun proses pengambilan data yang dilakukan dalam penelitian ini adalah:

1. Persiapan dan Pemeriksaaan Bahan Benda Uji

2. Pengujian Bahan Benda Uji

3. Penentuan Campuran

4. Pembuatan Benda Uji

5. Pengujian benda uji menggunakan Marshall test dan Wheel Tracking

\section{ANALISA DAN PEMBAHASAN}

Dari hasil Analisa didapatkan kadar bahan tambah optimum Derbo 0,3\% memperoleh hasil Density 2,423, VIM 3,657\%, VMA 15,257\%, VFA 76,128\%, Stabilitas 1139,77kg, Flow 2,73mm, Marshall $421,877 \mathrm{~kg} / \mathrm{mm}$. Sedangkan kadar bahan tambah optimum Wetfix 0,3\% memperoleh hasil Density 2,423, VIM 4,410, VMA 15,919\%, VFA 72,536, Stabilitas 1065,92kg, Flow 2,93mm, Marshall $363,986 \mathrm{~kg} / \mathrm{mm}$.

\begin{tabular}{|c|c|c|c|c|c|c|}
\hline $\begin{array}{l}\text { Sifat-sifat } \\
\text { campuran }\end{array}$ & \multicolumn{5}{|c|}{ Hasil Pengujian } & \multirow{2}{*}{ Spesifikasi } \\
\hline $\begin{array}{c}\text { Kadar Aspal } \\
(\%)\end{array}$ & 4,5 & 5 & 5,5 & 6 & 6,5 & \\
\hline Density & 2.469 & 2.451 & 2.434 & 2.417 & 2.400 & $\geq 2.2 \mathrm{~kg} / \mathrm{mm} 3$ \\
\hline VIM; \% & 6.525 & 5.331 & 4.233 & 3.436 & 2.709 & $\geq 3-6 \%$ \\
\hline VMA; \% & 15.049 & 15.027 & 15.102 & 15.449 & 15.860 & $\geq 15 \%$ \\
\hline VFA; \% & 57.570 & 64.841 & 72.249 & 78.492 & 84.598 & $\geq 63 \%$ \\
\hline Stabilitas; kg & 911.46 & 999.73 & 1061.08 & 1016.06 & 878.08 & $800-1800 \mathrm{~kg}$ \\
\hline Flow; mm & 3.37 & 2.87 & 2.39 & 2.69 & 3.35 & Min $2-4 \mathrm{~mm}$ \\
\hline
\end{tabular}



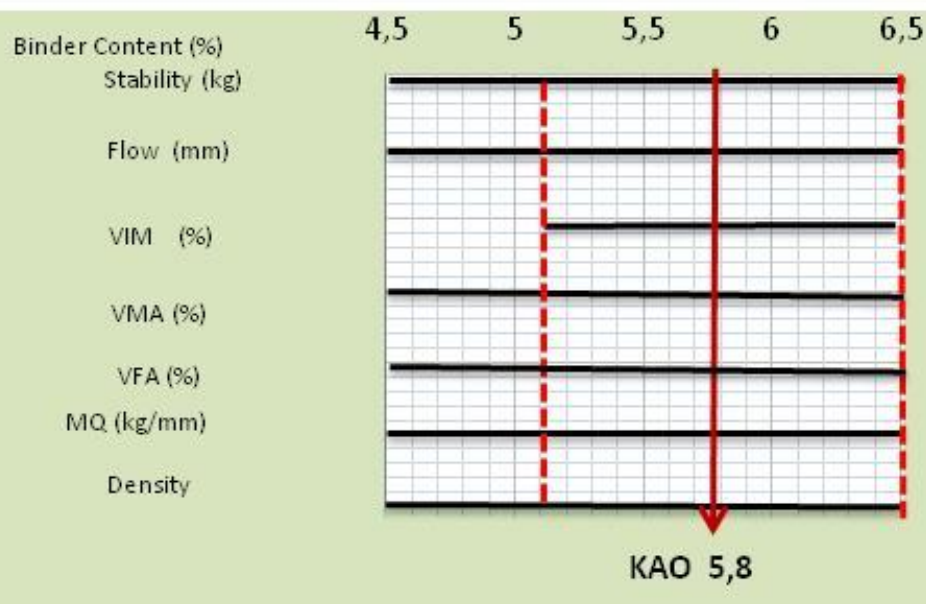

Gambar 2. Grafik Penentuan Nilai KAO Aspal Pertamina Pen 60/70

Dari hasil analisa grafik 4.8 Barchat hubungan kadar aspal aspal dengan karakteristik campuran di gunakan nilai tengah pada grafik yang memenuhi karakteristik Marshal Test, sehingga diperoleh KAO sebesar $5,8 \%$

$$
K A O=\frac{5,1 \%+6,5 \%}{2}=5,8 \%
$$

Tabel 2 Rekapitulasi Pengujian Marshall Campuran AC-WC pen 60/70 Terhadap Penggunaan Bahan Tambah Berdasarkan KAO.

\begin{tabular}{|c|c|c|c|c|c|c|c|c|c|c|c|}
\hline Sifat-sifat & \multicolumn{10}{|c|}{ Hasil Pengujian } & \multirow{2}{*}{$\begin{array}{c}\text { Spesifi } \\
\text { kasi }\end{array}$} \\
\hline \multirow{2}{*}{$\begin{array}{c}\text { Bahan } \\
\text { Tambah } \\
(\%)\end{array}$} & \multicolumn{2}{|c|}{ 0 } & \multicolumn{2}{|c|}{0,1} & \multicolumn{2}{|c|}{0,3} & \multicolumn{2}{|c|}{0,5} & \multicolumn{2}{|c|}{0,6} & \\
\hline & D & $\mathbf{W}$ & D & $\mathbf{W}$ & D & W & D & $\mathbf{W}$ & D & $\mathbf{W}$ & \\
\hline Density & 2,423 & 2,423 & 2,423 & 2,423 & 2,423 & 2,423 & 2,423 & 2,423 & 2,423 & 2,423 & $\begin{array}{c}\geq 2,2 \\
\mathrm{~kg} / \mathrm{mm} \\
3\end{array}$ \\
\hline VIM; \% & 5,212 & 5,212 & 4,409 & 4,870 & 3,657 & 4,410 & 3,875 & 4,021 & 4,125 & 3,788 & $\geq 4-6 \%$ \\
\hline VMA; \% & 16,625 & 16,62 & 15,919 & 16,324 & 15,257 & 15,920 & 15,449 & 15,577 & 15,669 & $\begin{array}{l}15,37 \\
2\end{array}$ & $\geq 15 \%$ \\
\hline VFA; $\%$ & 71,396 & 71,396 & 72,401 & 70,203 & 76,128 & 72,357 & 75,071 & 74,198 & 73,904 & $\begin{array}{l}75,35 \\
9\end{array}$ & $\geq 63 \%$ \\
\hline $\begin{array}{l}\text { Stabilitas; } \\
\text { kg }\end{array}$ & 1102,198 & $\begin{array}{c}1102,1 \\
98\end{array}$ & $\begin{array}{c}1176,7 \\
69\end{array}$ & $\begin{array}{c}1144,1 \\
99\end{array}$ & $\begin{array}{c}1262,3 \\
03\end{array}$ & $\begin{array}{c}1225,2 \\
20\end{array}$ & $\begin{array}{c}1164,2 \\
33\end{array}$ & $\begin{array}{c}1163,9 \\
91\end{array}$ & $\begin{array}{c}939,35 \\
1\end{array}$ & $\begin{array}{c}1123 \\
319\end{array}$ & $\begin{array}{l}800- \\
1800 \\
\mathrm{~kg}\end{array}$ \\
\hline Flow; mm & 3,333 & 3,333 & 2,933 & 3,233 & 2,733 & 2,933 & 3,100 & 3,300 & 3,623 & 3,433 & $\begin{array}{c}\text { Min 2- } \\
4 \mathrm{~mm}\end{array}$ \\
\hline $\begin{array}{l}\text { Hasil bagi } \\
\text { marshall; } \\
\mathrm{kg} / \mathrm{mm}\end{array}$ & 331,583 & $\begin{array}{c}331,58 \\
3\end{array}$ & $\begin{array}{c}442,09 \\
7\end{array}$ & $\begin{array}{c}352,35 \\
7\end{array}$ & $\begin{array}{c}467,17 \\
6\end{array}$ & $\begin{array}{c}418,39 \\
7\end{array}$ & $\begin{array}{c}375,06 \\
0\end{array}$ & $\begin{array}{c}353,62 \\
2\end{array}$ & $\begin{array}{c}260,93 \\
7\end{array}$ & $\begin{array}{c}327,1 \\
47\end{array}$ & $\begin{array}{l}\text { Min } \\
250\end{array}$ \\
\hline
\end{tabular}

Sumber dari hasil analisis dan pembahasan (2018)

Berdasarkan hasil pengujian, maka diperoleh nilai kadar Zat aditif derbo dan wetfix terhadap karateristik campuran seperti pada tabel 4.14. Dari hasil pengujian tersebut kita dapat mengetahui pengaruh penambahan Zat aditif derbo dan wetfix terhadap pengujian marshall test. Semua nilai hasil pengujian dimasukkan ke dalam grafik untuk mengetahui perlakuan yang terjadi sesuai dengan hubungan antara kadar Zat aditif derbo dan wetfixterhadap karakteristik campuran tersebut. 


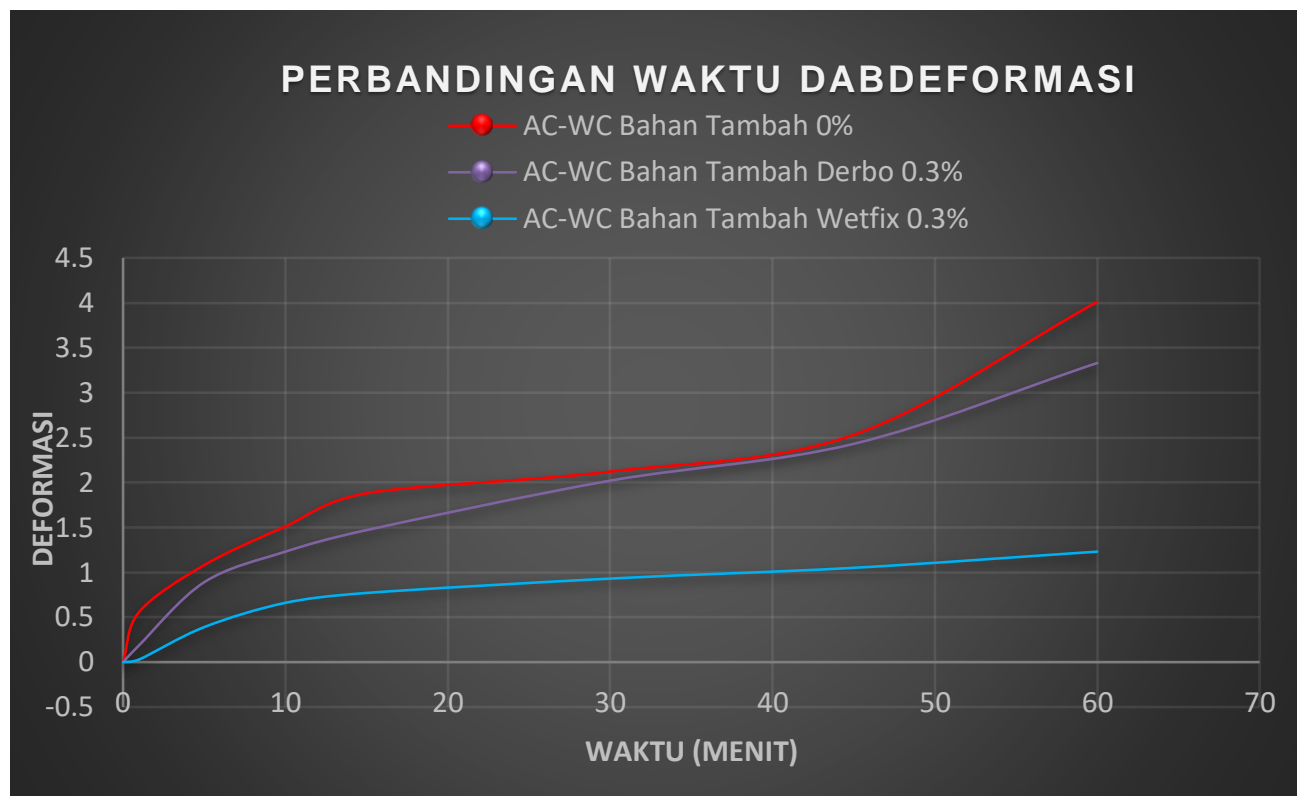

Gambar 3. Grafik Hasil Pengujian Hubungan Perbandingan Waktu dan Deformasi

Berdasarkan grafik 4.16 dapat dilihat zat Aditif wetfix mengalami penurunan Deformasi dibandingkan zat Aditif Derbo. Hal ini terjadi akibat perubahan dari sifat mekanik aspal yang telah di modifikasi dengan bahan tambah

Semakin lamanya waktu pembebanan dan jumlah lintasan yang dilakukan terhadap campuran menunjukkan peningkatan deformasi yang terjadi terlihat dari waktu pembebanan, jumlah lintasan dan nilai deformasi.

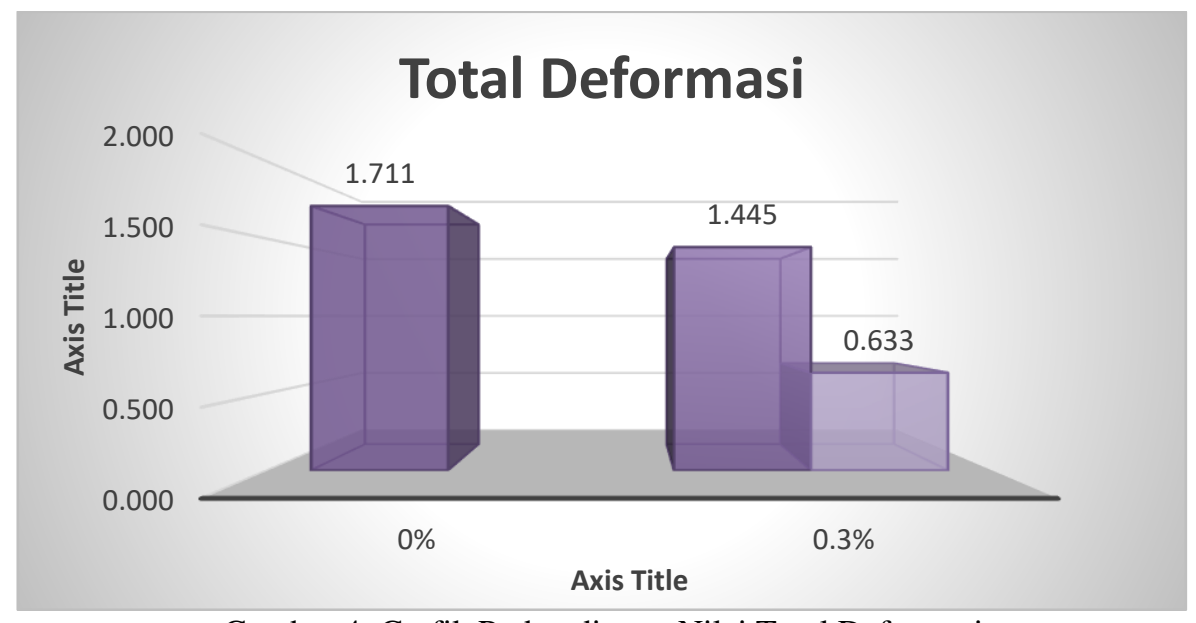

Gambar 4. Grafik Perbandingan Nilai Total Deformasi

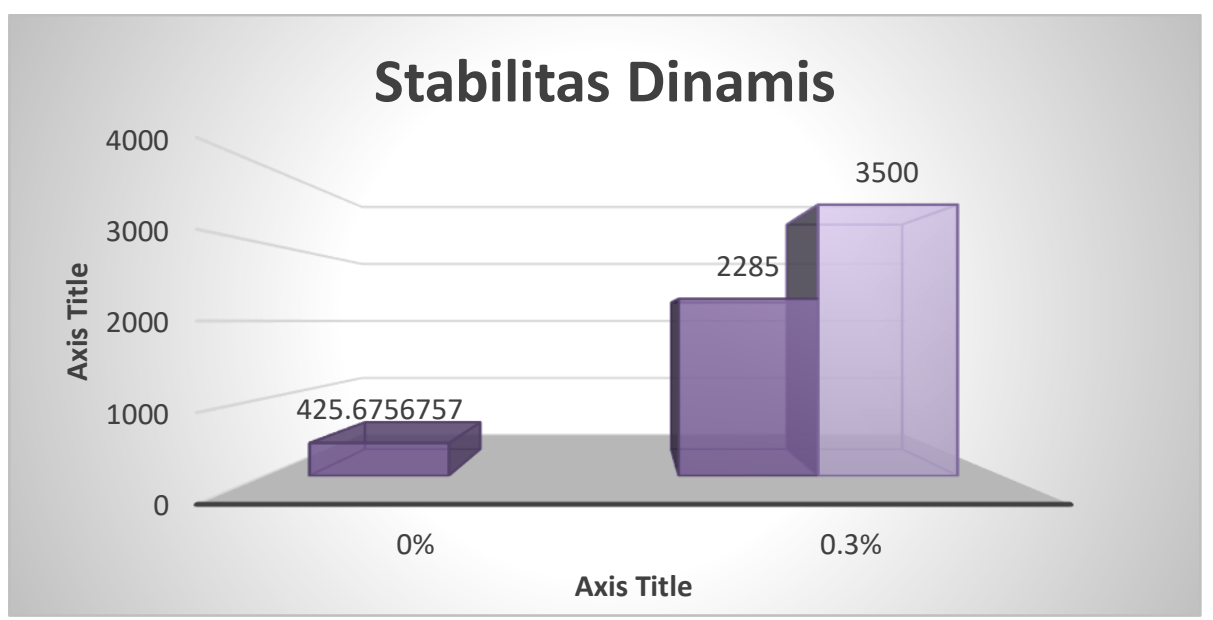


Gambar 5. Grafik Perbandingan Nilai Stabilitas Dinamis

Dari grafik 4. dapat dijelaskan pada campuran dengan menggunakan bahan tambah mengalami peningkatan stabilitas dinamis, dari grafik terlihat jelas penambahan zat aditif Wetfix mempunyai stabilitas dinamis yang paling besar yaitu 3500 liintasan/mm dengan demikian zat aditif Wetfix mempunyai stabilitas dinamis yang lebih baik dibandingkan Zat Aditif Derbo

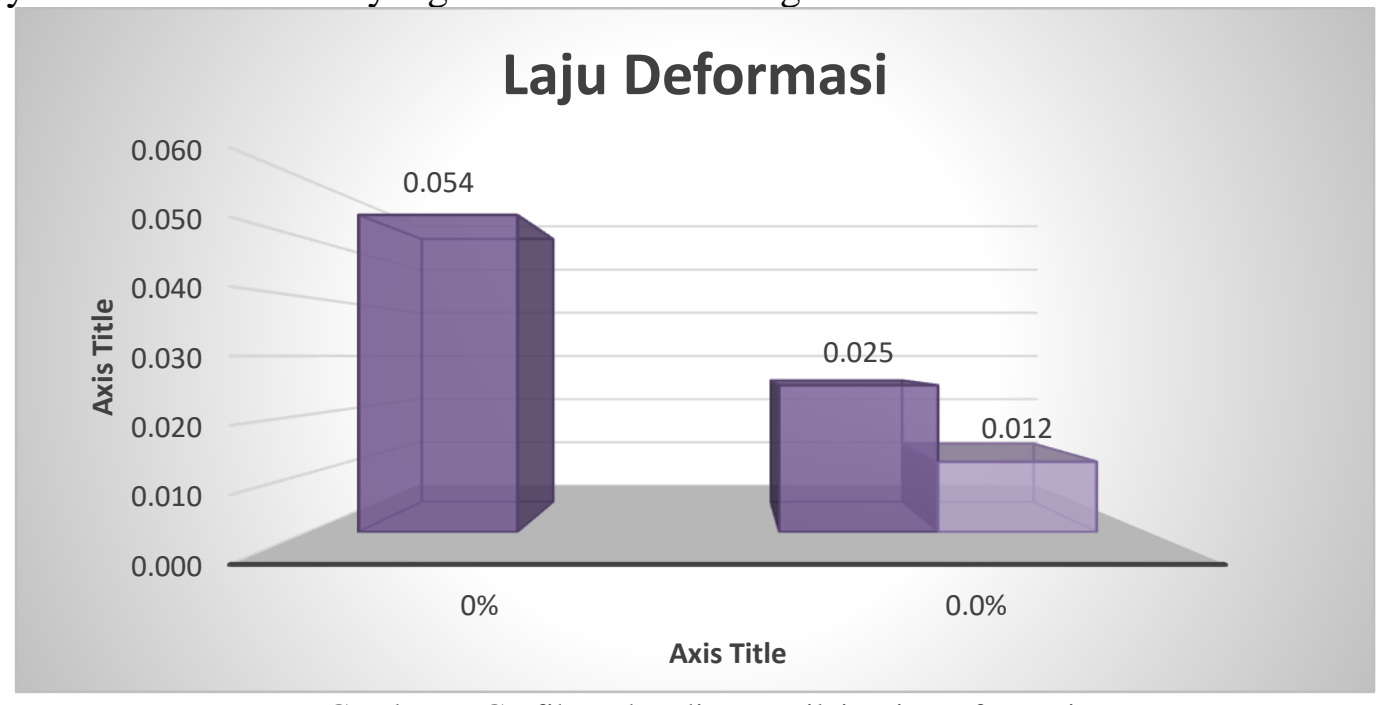

Gambar 6. Grafik Perbandingan Nilai Laju Deformasi

Dari grafik 5 dapat dijelaskan bahwa pada penambahn zat aditif Wetfix menunjukan kecepatan deformasi dalam satuan $\mathrm{mm} /$ menit mempunyai nilai yang paling kecil yaitu $0.012 \mathrm{~mm} / \mathrm{menit}$, hal ini disebabkan zat aditif wetfix mempunyai Stabilitas dinamis yang besar sehingga memperkecil kecepatan deformasi yang terjadi.

\section{PENUTUP}

\section{Kesimpulan}

Berdasarkan hasil penelitian Analisa Deformasi Pada Campuran Aspal Beton Dengan Menggunakan Derbo dan Wetfix dapat disimpulkan sebagai berikut:

1. Dari hasil Analisa didapatkan kadar bahan tambah optimum Derbo 0,3\% memperoleh hasil Density 2,423, VIM 3,657\%, VMA 15,257\%, VFA 76,128\%, Stabilitas 1139,77kg, Flow 2,73mm, Marshall $421,877 \mathrm{~kg} / \mathrm{mm}$. Sedangkan kadar bahan tambah optimum Wetfix 0,3\% memperoleh hasil Density 2,423, VIM 4,410, VMA 15,919\%, VFA 72,536, Stabilitas 1065,92kg, Flow 2,93mm, Marshall 363,986kg/mm.

2. Dari hasil Analisa didapatkan total deformasi derbo sebesar $1,445 \mathrm{~mm} /$ menit,sedangkan wetfix sebesar $0,633 \mathrm{~mm} / \mathrm{menit}$

\section{Saran}

Berdasarkan hasil penelitian di usulkan beberapa saran sebagaiberikut

1. Disarankan untuk penelitian selanjutnya untuk meneliti dengan menggunakan jenis aspal yang bervariasi,untuk mengetahui apakah penggunaan Derbo dan Wetfix baik digunakanpada jenis aspal yang berbeda atau tidak

2. Penelitian ini diharapkan dapat dikembangkan lebih lanjut untuk meneliti lebih mendalam pengaruh penggunaan Derbo dan Wetfix sebagai bahan tambah pada lapisan AC-WC, maupun jenis lapisan perkerasan lain.

\section{DAFTAR PUSTAKA}

Badaron, S. F., Gecong, A., Anies, M. K., Achmad, W. M., \& Setiani, E. P. (2019). Studi Perbandingan Kuat Tarik Tidak Langsung terhadap Campuran Aspal Beton dengan menggunakan Limbah Marmer dan Abu Sekam Padi sebagai Filler. PENA TEKNIK: Jurnal Ilmiah Ilmu-Ilmu Teknik, 4(2), 145-155.

Chalid, N. I. (2016). Karakteristik Campuran Aspal Hrs-Base Menggunakan Agregat Kasar Batu Kapur Asal Tinoring. Pena Teknik: Jurnal Ilmiah Ilmu-Ilmu Teknik, 1(1), 81-94. 
Fisu, A. A. (2019). Tinjauan Kecelakaan lalu Lintas Antar Wilayah Pada Jalan Trans Provinsi Sulawesi Selatan. PENA TEKNIK: Jurnal Ilmiah Ilmu-ilmu Teknik, 4(1), 53-65.

Hafidz, M. D. (2020). EFEKTIVITAS PENGGUNAAN BAHAN ANTI-STRIPPING WETFIX BE TERHADAP KARAKTERISTIK CAMPURAN ASPAL PORUS (THE EFFECTIVENESS OF USING WETFIX BE ANTI STRIPPING MATERIALS ON CHARACTERISTICS OF POROUS ASPHALT MIXTURE) (Doctoral dissertation, universitas islam indonesia).

Huwae, M., Kaseke, O. H., \& Sendow, T. K. (2015). Kajian Kinerja Campuran Lapis Pondasi Jenis Lapis Tipis Aspal Beton-Lapis Pondasi (HRS-Base) Bergradasi Senjang Dengan Jenis Lapis Aspal Beton-Lapis Pondasi (AC-Base) Bergradasi Halus. Jurnal Sipil Statik, 3(3).

Muaya, G. S., Kaseke, O. H., \& Manoppo, M. R. (2015). Pengaruh Terendamnya Perkerasan Aspal oleh Air Laut yang Ditinjau Terhadap Karakteristik Marshall. Jurnal Sipil Statik, 3(8).

Rizal, R. S., Susilowati, A., \& Susanto, H. (2019). KAJIAN PENGGUNAAN WETFIX BE PADA BETON ASPAL CAMPURAN PANAS BERGRADASI SUPERPAVE. Jurnal Ilmiah Teknologi Infomasi Terapan, 5(2), 66-74.

Röder, H., Hahn, E., Brune, H., Bucher, J. P., \& Kern, K. (1993). Building one-and two-dimensional nanostructures by diffusion-controlled aggregation at surfaces. Nature, 366(6451), 141-143.

Sudarno, S., Fadhilah, L., Afif, A., Nurobingatun, S., Hariyadi, H., \& Mufid, A. (2018). ANALISIS TEBAL PERKERASAN JALAN RAYA MAGELANG-PURWOREJO KM 8 SAMPAI KM 9 MENGGUNAKAN METODE BINA MARGA 1987. Reviews in Civil Engineering, 2(1).

Sulaiman, L., \& Fisu, A. A. (2020). Pengaruh Campuran Terhadap Kuat Tekan Beton Agregat Recycle. Rekayasa Sipil, 14(1), 35-42.

Sulaiman, L., Sedek, M., Maing, S., \& Fisu, A. A. (2018, December). Studi Kuat Tekan Beton Recycle Agregat Dengan Campuran Air Laut. In Seminar Nasional Hasil Penelitian \& Pengabdian Kepada Masyarakat (Snp2m).

Susilowati, A., \& Wiyono, E. (2017). Penggunaan Bahan Anti Stripping untuk Campuran Beton Aspal. Jurnal Poli-Teknologi, 16(1).

Syaifullah, S. (2016). Variasi Komposisi Gradasi Batuan terhadap Karakteristik Beton Aspal dengan Uji Marshall. PENA TEKNIK: Jurnal Ilmiah Ilmu-Ilmu Teknik, 1(2), 163-174.

Van Der Walt, J. D., Scheepbouwer, E., \& Tighe, S. L. (2018). Differential rutting in Canterbury New Zealand, and its relation to road camber. International Journal of Pavement Engineering, 19(9), 798-804. 